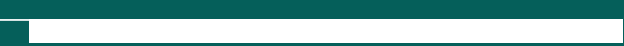

SECCIÓN: Problemas espaciales contemporáneos
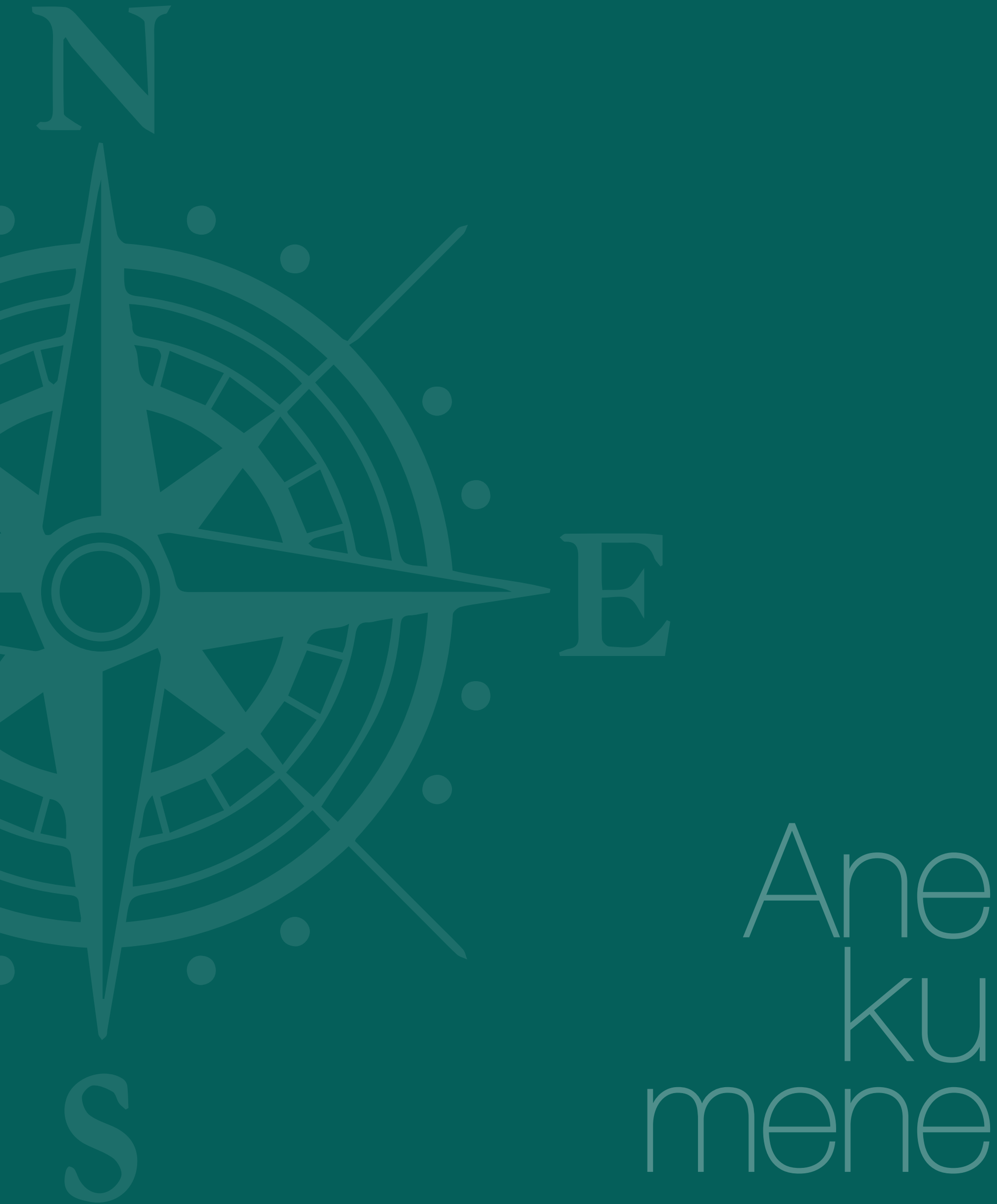


\section{O raciocínio espacial na educação infantil}

\section{El razonamiento espacial en la educación infantil Spatial Reasoning in Early Childhood Education}

Paula Cristiane Strina Julias*

\section{Resumo}

A linguagem cartográfica é cada dia mais utilizada e acessível por causa das tecnologias. As pessoas acostumam, no dia-a-dia, revisar um mapa ou traçar uma rota em um aplicativo GPS nos seus telefones. A compreensão de um mapa implica orientação, localização e direção, não acontece de forma natural e espontânea. Sabemos que esse tipo de conhecimento é o resultado do desenvolvimento de habilidades do pensamento e mais especificamente do modo de pensar o espaço, razão pela qual consideramos necessário e valioso refletir sobre este tema e panorama na sociedade e geografia atual.

\section{Palavras-chave}

ensino da Geografia; linguagem cartográfica; raciocínio espacial

* Doutoranda na Faculdade de Educação da Universidade de São Paulo (FEUSP). 


\section{Resumen}

El lenguaje cartográfico es cada vez más utilizado y accesible; gracias a las tecnologías, las personas se acostumbran cotidianamente a consultar un mapa o a trazar una ruta en una aplicación en el celular con GPS. La comprensión de un mapa implica orientación, localización y dirección y no se da de forma natural y espontánea. Sabemos que este tipo de conocimiento es el resultado del desarrollo de habilidades del pensamiento y más específicamente del modo de pensar el espacio, razón por la cual consideramos necesario y valioso reflexionar este tema y panorama en la sociedad y geografía actual.

\section{Abstract}

Cartopraphic language is increasingly used and accesible; due to technology, people are used to consult a map or trace a route in a cellphone app with GPS on a daily basis. Understanding a map means orientation, localisation and direction which are not given naturally or espontaneously. We know this type of knowledge results from the development of thinking abilities and specifically, from spatial reasoning. For this, we consider necessary and valuable to reflect on this subjet and outlook in current society and geography.

\section{Palabras clave}

enseñanza de la geografía; lenguaje cartográfico; razonamiento espacial

\section{Keywords}

geography teaching; cartographic language: spatial reasoning 
A linguagem cartográfica tem sido cada vez mais utilizada e acessível por meio das tecnologias e as pessoas, devido as mais diversas razões, se habituam cotidianamente a consultar um mapa ou a traçar uma rota em um aplicativo no celular com GPS. A compreensão de um mapa de deslocamento envolve orientação, localização e direção e não se dá de forma natural e espontânea. Sabemos que este tipo de conhecimento é resultado do desenvolvimento de habilidades do pensamento e mais especificamente do modo de pensar o espaço.

Além deste tipo de uso da linguagem cartográfica, ela nos permite, aliada ao conhecimento geográfico, compreender os arranjos e conexões espaciais de fenômenos e lugares em um dado momento.

Após o período em que a Cartografia foi vista como uma ciência exata e objetiva, coisa para experts e, portanto, relegada aos especialistas, vivemos atualmente um período de (re) valorização dos conhecimentos cartográficos como meio de aprimorar a compreensão e a representação do espaço em que vivemos. (Lastória, Moraes e Fernandes, 2013, p. 115).

Desta forma, tomamos o contexto atual da geografia caracterizado por diversas linguagens e diversos universos, como o tecnológico, que perpassam por toda cultura escolar, uma vez que estão no cotidiano de alunos e professores. Portanto, em um meio técnico-científico-informacional, a geografia cumpre o papel de desenvolver um espiríto crítico, estabelecendo relações entre o lugar, a formação sócio-espacial e o mundo.

Com base na neurociência, Gersmehl (2008) afirma que as recentes pesquisas indicam que o pensamento espacial é formado por oito processos: comparação espacial, influência espacial, grupos espaciais (regiões), transição espacial, hierarquia espacial, analogia espacial, padrões espaciais e associações espaciais. Estes processos ocorrem em diferentes partes do cérebro e envolvem também diferentes redes da memória, não consistindo em um único tipo isolado de inteligência.

Neste artigo, discutiremos principalmente duas destas habilidades: comparação e transição espacial. Com base em estudos sobre crianças na Educação Infantil, Gersmehl e Gersmehl (2007) concluem que a comparação atua como uma ponte para outros modos de pensamento espacial, pois permite pensar sobre condições e conexões entre novos lugares e aqueles já conhecidos. A questão essencial para a geografia é: como os lugares são semelhantes ou diferentes?

A transição espacial está relacionada as noções de tempo e espaço conjuntamente, por meio da sequência de lugares ou coisas e tem a palavra "entre" como chave no modo de pensar. Assim, a sequência espacial é um componente essencial para leitura e a matemática, por exemplo, as letras em uma palavra, e palavras em uma sentença e sentenças em um parágrafo estão organizados em uma sequência espacial. (Gersmehl e Gersmehl, 2007). Isso também está relacionado à memorização de um caminho e os lugares que o compõem, pois basicamente consiste na mudança de um lugar para outro. A questão principal é: o há entre os elementos (lugares, por exemplo) no espaço?

Os desenhos das crianças, enquanto concretização destas formas de raciocínio, refletem o que pensam sobre uma proposta espacial, ou seja, suas representações. A partir do desenho da criança podemos compreender qual é o ponto de vista usado para representar algo a partir de uma problemática relacionada a alguma das habilidades do pensamento espacial, como a influência espacial. É possível inferir como a transição de um lugar para o outro em um desenho toma sentido e se a criança coordena posições e planos ou, ainda, quais recursos gráficos são usados para representar uma hierarquia espacial.

A representação gráfica do espaço em relação ao volume pode ser definida por quatro etapas, segundo Greig (2004): ponto de vista único, conjunção sincrética com seus rebatimentos, busca de profundidade e a perspectiva convencional. 0 ponto de vista único está relacionado a justaposição e estereotipias, a conjunção sincrética (rebatimento e transparência) tem base na sobreposição e materialização da ação e a busca de profundidade relaciona-se com a coordenação, interrupção-continuidade das posições e dos planos, por exemplo o desenho de uma faca que corta uma fruta.

De acordo com Greig (2004), uma linha de céu ou uma faixa de nuvens, uma linha de solo ou uma platibanda de hastes de grama ou de flores introduzem, às vezes precocemente, as três faixas de sua estruturação gráfica mais habitual. 0 estudo da representação destas três faixas (solo, espaço vazio e céu) torna-se pertinente à nossa investigação, pois são fatores que estabelecem a relação espacial no desenho e permitem compreender se as crianças inserem elementos que auxiliam na mudança do ponto de vista.

Greig (2004) afirma que a relação entre os elementos em um desenho fornece suporte para sucessivos avanços de representação do espaço e pergunta se a linha do horizonte não consiste em um valor relacional muito expressivo de fusão, contato, barreira ou conflito. É neste sentido que buscamos compreender o uso destas linhas pelas crianças e como se relacionam com as habilidades do raciocínio espacial. Portanto, temos como suporte a proposta de análise formulada por Greig sobre a organização de volumes e de espaço por meio das etapas e características, representadas na figura 1 .

Neste contexto, a Cartografia corresponde a uma linguagem que, na infância, conta com diversas manifestações tendo vista as muitas linguagens expressivas, como brincadeira de faz-de-conta, materiais concretos, colagens e desenhos. Por meio da pesquisa de doutorado "A relação espaço-tempo e a Cartografia na Infância"1, investigamos a relação entre

1 Pesquisa financiada pela Fundação de Amparo à Pesquisa do Estado de São Paulo (FAPESP), com orientação de Sonia Maria Vanzella Castellar, na Faculdade de Educação da Universidade de São Paulo (FEUSP). 


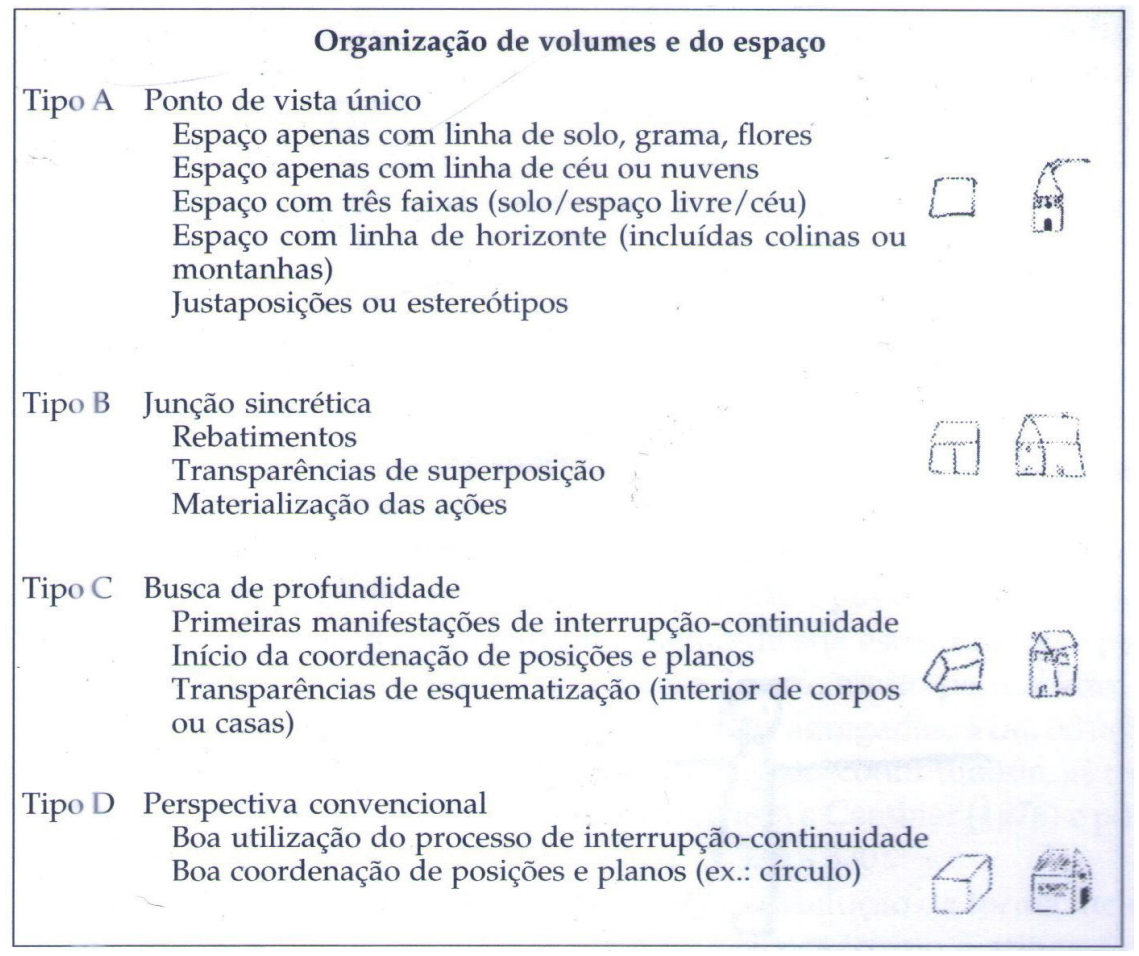

Figura 1. Componentes da organização de volumes e de espaço.

Fonte: Greig, 2004.

pensamento espacial, geografia e cartografia na educação infantil, partindo da pergunta orientadora: quais habilidades espaciais e princípios geográficos podem ser envolvidos em atividades para o desenvolvimento do pensamento espacial de crianças de 4 a 6 anos?

Para responder a esta questão, estabelecemos quatro etapas: desenvolver situações de ensino - com base no universo infantil, nos conceitos de mediação e fala de Vigotski (2009), nas habilidades do pensamento espacial propostas por Gersmehl (2008) e nos estudos de Greig (2010) sobre o desenho infantil; compreender os padrões estabelecidos nas representações gráficas realizadas pelas crianças; compreender os diálogos e investigar a pertinência e a abordagem das noções espaciais no currículo oficial da Educação Infantil.

Ao longo da pesquisa, desenvolvemos três sequências didáticas centradas nas habilidades do pensamento espacial propostas por Gersmehl (2008) e buscamos compreender as produções das crianças em cada uma delas como resultado de seu pensamento sobre a problemática espacial proposta. Neste artigo, objetivamos apresentar uma destas sequências desenvolvida com crianças de 4 a 6 anos em duas escolas, uma pública e outra filantrópica, na cidade de São Paulo
Tivemos como foco as habilidades de comparação e transição e, também, a participação das crianças de forma ativa e criativa no decorrer da sequência. Além disto, procuramos discutir os padrões estabelecidos nas representações gráficas, analisando a organização do espaço realizada pelas crianças e tomamos o conceito de localização como central nesta sequência, mobilizando o pensamento sobre a existência de elementos abaixo da superfície de vivência das crianças, com o enfoque nas noções elementares de acima e abaixo.

Então, por que estudar habilidades do pensamento espacial na educação infantil, se a geografia passa a ser desenvolvida em anos posteriores da vida escolar? É frequente observarmos, por exemplo, uma criança manuseando letras em material tridmensional ou fazendo sequências com blocos lógicos em uma sala de educação infantil, atividades que introduzem conceitos do letramento e da matemática. Por outro lado, não existem direcionamentos teóricos e práticos para atividades que introduzem noções geográficas em turmas compostas por crianças pequenas de 4 a 6 anos. Esta lacuna pode promover deslocamento de atividades adequadas ao ensino fundamental para educação infantil. 
Para desenvolver de fato uma aproximação entre o conhecimento pessoal com o conhecimento científico, na educação infantil, é necessário refletir sobre a integração entre as etapas da educação básica, a medida que esta se tormou obrigatória a partir dos 4 anos de idade.

Arce (2010), quando a educação infantil a partir dos 4 anos de idade não era obrigatória, já indicava esta necessidade de articular as diferentes etapas.

Acreditamos que o primeiro requisito para a integração entre o ensino fundamental e a educação infantil resida na estruturação pedagógica desse segmento educacional, estruturação esta calcada na compreensão científica de suas instituições (creches e pré-escolas) como contextos de aprendizagem e desenvolvimento, sustentados pelo planejamento de conteúdos e procedimentos de ensino adequados à faixa etária a que se destinam. (p.60).

Com base nisso, nossa pesquisa se ocupa em compreender o que é possível desenvolver com a crianças de 4 a 6 anos de idade, em relação a iniciação cartográfica, uma vez que consiste em uma linguagem usada principalmente nos estudos geográficos e como o conhecimento geográfico pode ser acessível às crianças.

Tabela 1. Síntese da sequência de atividades realizadas.

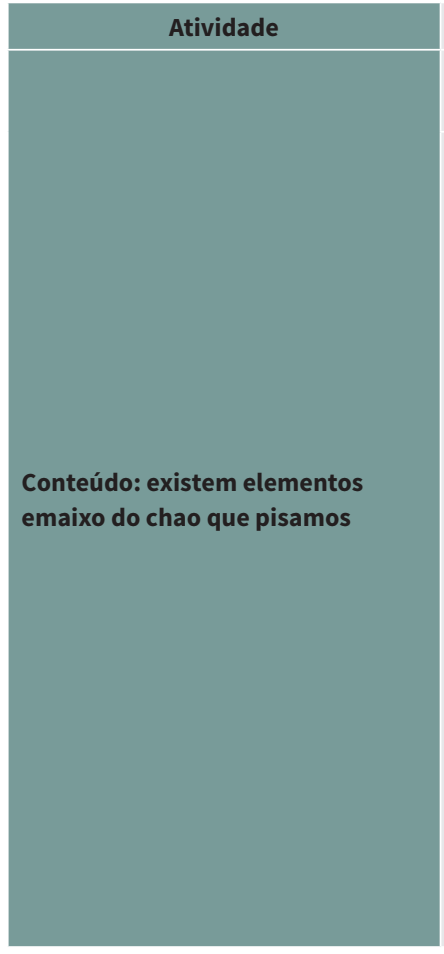

Se não tivesse terra, a gente pisava onde?

Objetivo

Refletir sobre a importância e a existência do chão.

\section{Dinâmica}

a) Conversa sobre o que pode existir embaixo da cama;

b) Leitura do texto "Se nao existisse terra, a gente pisava onde?" (Azevedo, 2009)

c) Em grupo, classificação das figuras em duas categorias diferentes: "em cima" e "embaixo" do chão;

d) Apresentação de cada grupo e colagem daas figuras em um cartaz;

e) Desenho colectivo de outros elementos que podem existir embaixo do chão.

Raciocínio espacial

Comparação espacial

Transição espacial

\section{Metodologia}

Para responder às nossas perguntas, elaboramos uma sequência de atividades com o conceito central de localização, investigando como as crianças dessa faixa-etária estabelecem a relação em cima e embaixo a partir de um conteúdo geográfico, envolvendo as habilidades do pensamento espacial de transição e comparação.

A primeira atividade está centrada na sondagem do que as crianças sabem sobre o tema por meio de uma atividade coletiva de classificação de elementos do que pode existir em cima e embaixo do chão (Figura 2). $\mathrm{Na}$ atividade seguinte, o objetivo é compreender como as crianças estabelecem a relação em cima e embaixo no espaço gráfico de forma livre e se elas criam uma linha de base para estabelecer e organizar essas noções espaciais. Na terceira atividade, isto é problematizado a partir de uma linha de base com o objetivo de analisar como as crianças a usam e saber qual ponto de vista é usado por elas nas representações gráficas (Figura 3 ).

\section{Sequéncia e desenvolvimento}

O que existe embaixo da cama e 0 que existe embaixo da cama e embaixo do chão?

Objetivo

Compreender que existem elementos embaixo do chao.

\section{Dinâmica}

a) Conversa sobre o que pode existir embaixo da cama

b) Leitura do livro "debaixo de cama: uma viagem ao centro da Terra" (Manning \& Granströn, 2007);

c) Conversa sobre o que pode existir emaixo da cama e embaixo do chao

d) Desenho sobre o que existe embaixo do chão; embaixo da chão?

Objetivo

Localizar os elementos que podem existir embaixo da cama e do chão

\section{Dinâmica}

a) Conversa sobre a actividade anterior

b) desenho a partir da pergunta "O que existe embaixo da cama e embaixo da terra"

c) conversa sobre os desenhos

\section{Raciocínio espacial}

Comparação espacial

e) Conversa sobre as produçoes.

Transição espacial

\section{Raciocínio espacial}

Comparação espacial

Transição espacial 


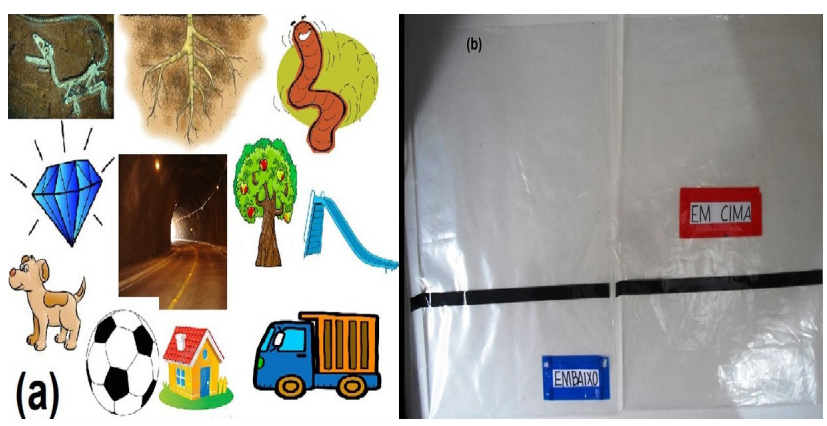

Figura 2. Materiais utilizados na primeira atividade: (a) figuras, (b) sacos pláticos para classificação. Fonte: elaboração própria.

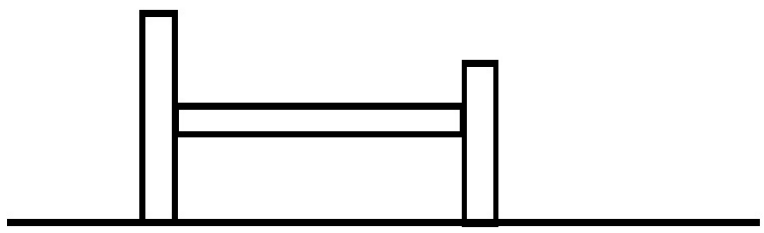

Figura 3. Desenho com linha de base

Fonte: elaboração própria.

Importante destacar que o planejamento destas atividades partiu da concepção de criança enquanto sujeito, que tem a educação como direito e a Educação Infantil como uma primeira aproximação ao conhecimento científico. É importante ressaltar que o objetivo de propostas de ensino nesta etapa não consiste no acúmulo ou no aprofundamento de conteúdo científico e preparação para o ensino fundamental, e, "sim o desenvolvimento da capacidade de perguntar, levantar hipóteses, buscar informações em fontes diversas, estabelecendo relações entre elas, elaborar ideias e argumentar" (Galian, 2012, p.22).

Esta sequência foi desenvolvida em duas escolas com crianças de 4 a 6 anos, ambas na cidade de São Paulo. Para o registro das atividades, lançamos mão do uso de câmera vídeo, instrumento essencial para o desenvolvimento de toda pesquisa, pois a filmagem permite captar com precisão a fala e os gestos dos alunos, o que nossa memória ou o campo visual no momento da coleta de dados não conseguem alcançar. (Carvalho, 2011).

Esta pesquisa está centrada nas seguintes fontes de dados, além da gravação em vídeo: a) notas de campo, que estão relacionados às percepções e conversas no momento da coleta que escapam das gravações; b) fotografias de aspectos que a câmera de vídeo pode não alcançar, pois tratando-se de salas de aulas, a câmera fotográfica pode registrar particularidades enquanto que o vídeo explora de forma mais ampla o ambiente; c) as produções das crianças, consistindo em uma rica fonte documental para responder as perguntas iniciais desta pesquisa.

As gravações são importantes e essenciais instrumentos para entender como as crianças constrõem as habilidades do raciocínio espacial, no entanto, para que a relação entre atividade empírica e teórica seja realizada, as gravações devem ser transformadas em dados. Ressaltamos que esta pesquisa trata as gravações como uma etapa da investigação, não consistindo em um único fim ou que suas transcrições já apresentam dados.

Os sentidos, a construção de dados, ocorrem a partir da interação do pesquisador, nós, com os cenários encontrados e provocados em campos, a sala de aula, e o desenvolvimento da sequência didática, ou seja, em uma relação estreita e constante diálogo entre a teoria e o material empírico. Entedemos que o pesquisador propõe o problema, a sequência didática e a conduz afim de responder sua principal questão, com base em seus critérios de análise.

\section{Resultados e discussões}

Ao longo do desenvolvimento desta sequência, verificamos que envolvemos as noções de comparação e transição espacial, pois a proposta permitiu pensar sobre dois espaços: a superfície e o subsolo, bem como na transição entre um e o outro.

Quando iniciamos a sequência de atividades com a pergunta se não existisse terra, a gente pisava onde? Algumas crianças disseram que todos voariam como $\mathrm{GAB}(6)^{2}$ que, com o objetivo de argumentar, explicou: "porque a rua fica no planeta e tem o espaço, se não tivesse o chão a gente voaria."

Observamos o uso de duas palavras que constituem a argumentação: se e porque. 0 uso da palavra "se" introduz a ideia de hipótese para um fato, características da alfabetização científica e "porque" refere-se a ideia de causa, o que também é tratado na investigação de um problema.

Outras crianças disseram que pisariam no "espaço sideral", na "cama", "no ar", "em nada", "no rio" e "no vento" e algumas procuravam solução dizendo "a gente mudava de planeta". Tivemos momentos em que as crianças fizeram relação com a sobrevivência no planeta: "a gente ia morrer sem água e terra”, segundo AGA $(5,8)$. Neste caso, a ideia de meio ambiente e a terra enquanto elemento fundamental para sobrevivência humana mostra-se mobilizada. É possível verificar que este tipo de pergunta invoca a ideia de vida na superfície do planeta em que vivemos.

2 As idades das crianças serão apresentadas no formado (anos, meses). 
A partir desta conversa, as crianças realizaram a classificação das figuras e alguns grupos entraram em debate em relação as figuras de diamante e túnel. Algumas crianças disseram que era possível encontrar diamante em cima do chão, em lojas, e outras afirmaram que ficava "enterrado", debaixo do chão.

No desenho coletivo realizado no cartaz, as crianças apresentaram elementos discutidos como túnel, minhoca, raiz de árvore e diamante juntamente com cobra, barata, pessoas mortas, diabo e água, coisas que ainda não tinhams surgido nas conversas. As crianças também desenharam alguns cenários com árvores, casas e pessoas e quando quetsionadas se aquilo fazia parte do subsolo, respondiam dizendo que não, porém tinham vontade de desenhar estes temas, muito comum no desenho infantil.

Na segunda atividade, quando conversamos sobre o que poderia existir debaixo da cama e do chão, algumas crianças disseram elementos, tratados pela história lida (Manning \& Granströn, 2007) como brinquedo, túnel, areia, cano, caverna, estação de trem e outros ainda não citados: água, terra, terremoto e diabo.

Durante a conversa, as crianças trouxeram suas memórias relatando o que havia debaixo das próprias camas: brinquedos, poeira, caixa de leite e diamantes. Então, propusemos que desenhassem em uma folha em branco o que havia embaixo da cama e embaixo do chão, com o objetivo de entender como organizariam o espaço gráfico e se usariam linha de base ou não.

Ao longo da conversa, duas crianças, GRA (6) e NIC (6) disseram que existia "uma rua debaixo" e notamos que eles estavam se referindo a forma que as pessoas geralmente dizem ao tratar uma rua que fica em níveis menos elevados em um terreno.

Esse equívoco relacionado a semântica é comum, pois comumente ouvimos rua de cima, rua de baixo ou olhe para cima antes de atravessar como relatado por Lorenzato (2006) no livro Educação Infantil e Percepção Matemática:

Como você sabe, criança tem mania de sair correndo à frente dos pais. Foi o que Rogério, de cinco anos, fez diante dos pais que gritaram apreensivamente: - Antes de atravessar a rua, olhe para cima e para baixo! Rogério que ia atravessar uma ladeira de forte inclinação, parou na sarjeta, olhou para o céu e depois para os seus pés e em seguida atravessou correndo a ladeira... sem verificar se vinha algum veículo ladeira abaixo (p. 185)

Nos desenhos, as crianças apresentaram tanto elementos reais e possíveis de encontrarmos debaixo do chão quanto elementos da imaginação e do desejo infantil. Buscando alcançar nosso objetivo específico de estudar os padrões estabelecidos pelas crianças e organizamos as produções da segunda atividade em quatro categorias: a) Linha de base: o desenho apresenta a linha do chão que fornece a base para estabelecer o que pode inserir embaixo da cama e o que fica embaixo do chão. (Figura 4).

b) sem linha de base com noção embaixo/em cima: a criança não estabelece uma linha gráfica como o chão, mas dispõe os elementos debaixo da cama. (Figura 5).

c) sem linha de base: o desenho apresenta elementos avulsos que existem debaixo do chão ou da cama, mas não expressa uma relação espacial. (Figura 6).

d) outro tema: o desenho apresenta outros temas. (Figura 7).

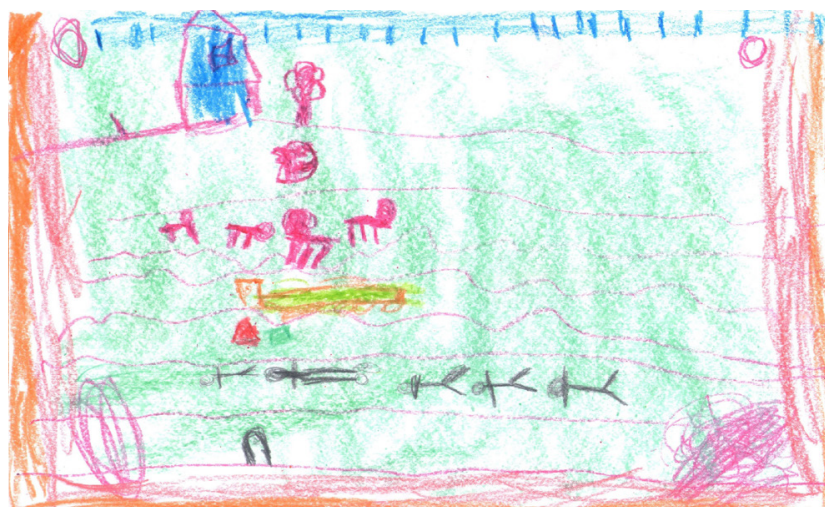

Figura 4. Desenho de NIC (6): categoria a

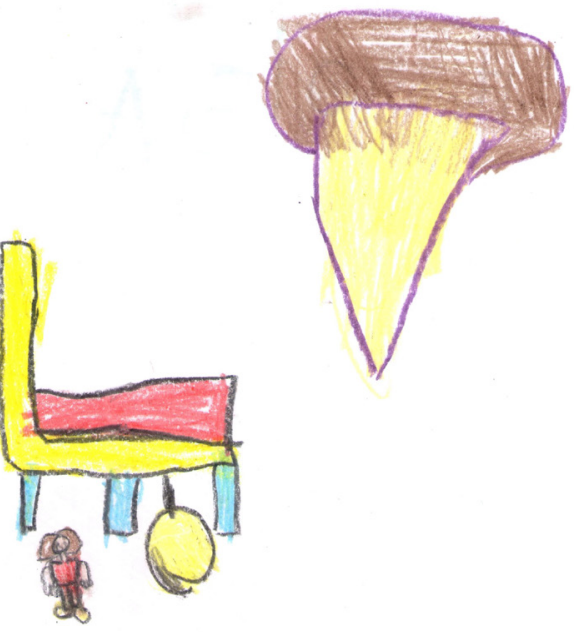

Figura 5. Desenho de HEL (6): categoria b. 


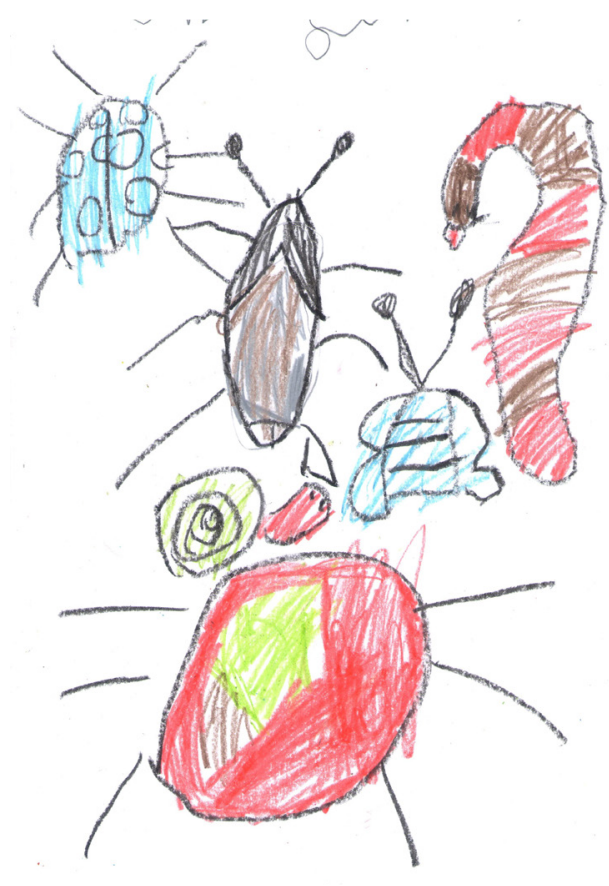

Figura 6. IAS (6): Categoria c

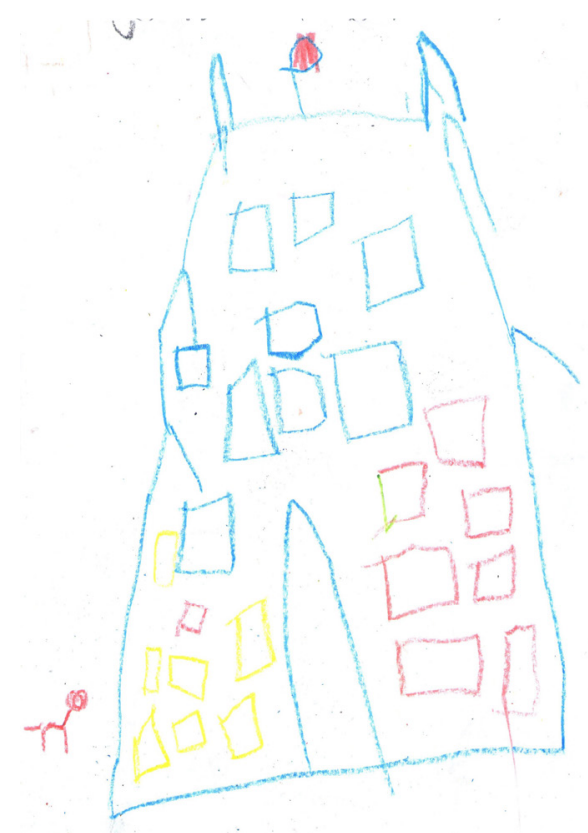

Figura 7. Desenho de JUL (6): Categoria d.
No desenho de NIC, é possível observar o estabelecimento da noção espaciais em cima e embaixo, a partir da linha do céu, do espaço e da linha do chão, porém a partir do conteúdo trabalhado a criança estabelece as linhas do subsolo. Estas linhas marcam a transição espacial, dos níveis mais próximo da superfície para as camadas mais profundas neste perfil realizado por NIC.

Na terceira atividade, as crianças disseram que debaixo do chão era possível ter areia, gente morta, fóssil de dinossauro, formiga, caverna e minhoca. Nos desenhos pudemos notar diversos elementos comentados nas conversas como pessoas mortas e trem e MIR desenhou um planeta debaixo do chão, afirmando que ficávamos no planeta.

Os desenhos da terceira atividade foram agrupados em duas categorias: a) o uso da linha de base na representação espacial: em alguns casos a criança usou a linha de base para estabelecer objetos embaixo da cama apenas e outros, usou a linha para estabelecer o que havia abaixo do chão também (Figura 8 e 9); b) sem uso da linha de base (Figura 10).

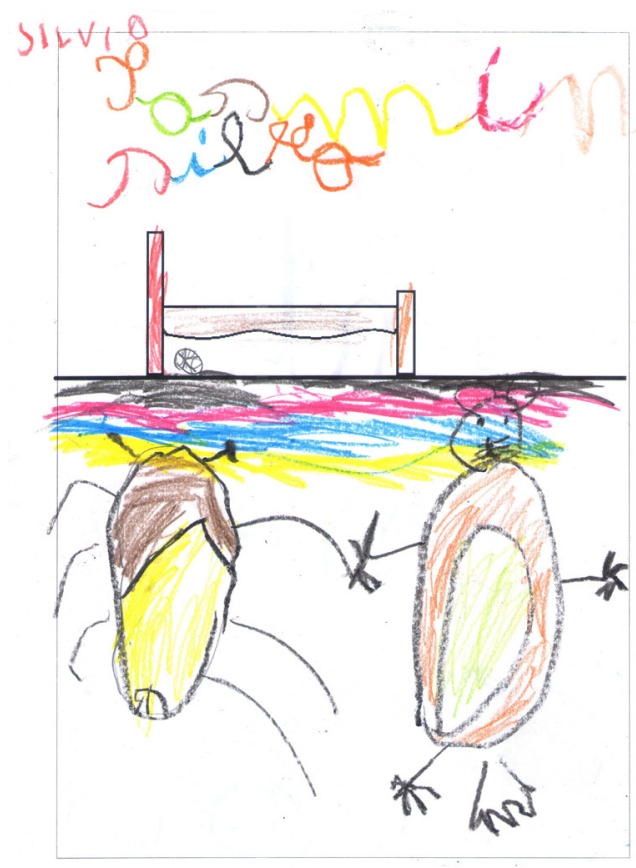

Figura 8. Desenho de IAS (6): uso da linha base 


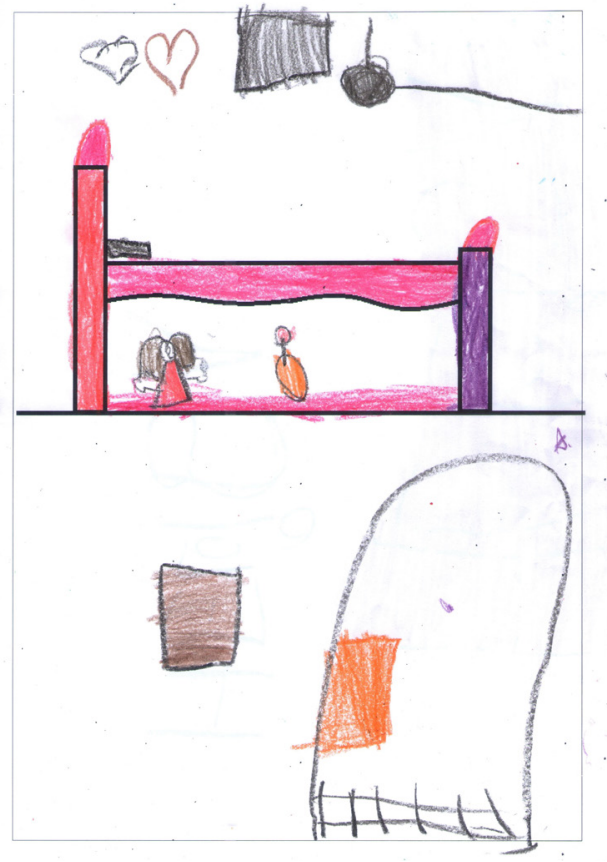

Figura 9. Desenho de HEL (6): uso da linha base

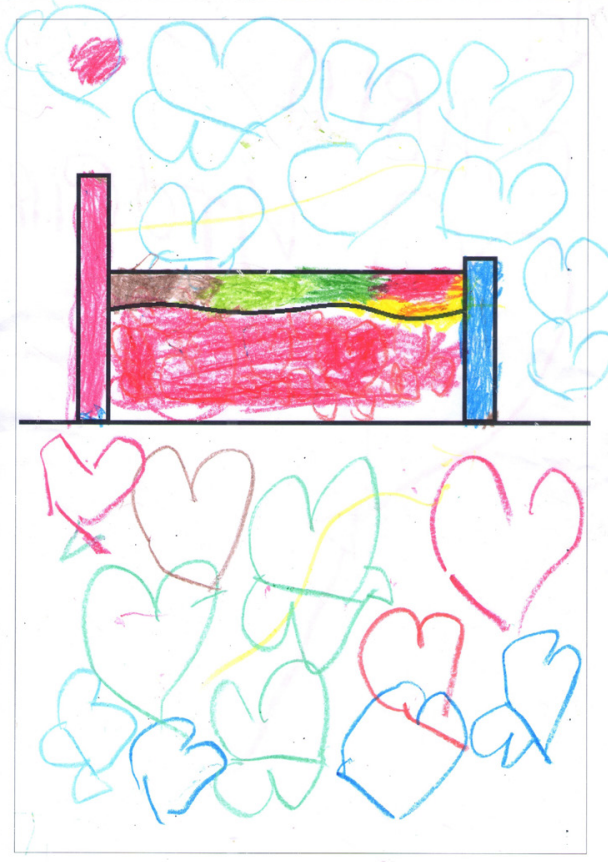

Figura 10. Desenho de MAV $(5,11)$ : sem uso da linha base
A existência de uma linha de base, o chão, induz o ponto de vista frontal, como podemos observar no túnel desenhado por HEL, além de delimitar a transição espacial. É possível notar as mais diversas formas de organização de volume e de espaço representadas pelas crianças, tanto na segunda quanto na terceira atividade. No desenho de IAS (6) ocorre a mistura de ponto de vista, nas figuras 6 e 8 a barata é representada vista de cima com as patas rebatidas, enquanto que o rato na figura 8 é desenhado conforme a visão frontal.

Atividades baseadas na "Transição Espacial", podem introduzir conceitos importantes para compreender por exemplo um perfil de solo em anos posteriores. Isso porque a sequência e a ordem estabelecida tanto pela história quanto na colagem e as palavras (embaixo, em cima e entre) introduzem noções de tempo e espaço conjuntamente, pois quando perguntamos o que há embaixo da cama estamos querendo saber o que há entre o chão e a cama.

A sequência apresentada mostrou que as noções topológicas devem estar baseadas no pensamento infantil, como na memória. Isso porque na determinação do conceito, o objeto do ato de pensar está constituído, para a criança, não tanto pela estrutura lógica dos próprios conceitos como pela lembrança, e a concretude do pensamento infantil, seu caráter sincrético, é outra faceta desse mesmo fato, que consiste em que o pensamento infantil se apóia principalmente na memória. (Vigotski, 1998).

É importante relacionarmos a memória à outra função psíquica: a imaginação. Isso porque a criança imagina com base nos dados da memória, para novas combinações. Nessa atividade, as noções de em cima e embaixo apresentadas na história demandaram imaginar os elementos que pudessem estar embaixo da cama, em uma determinada sequência.

\section{Considerações}

As análises apresentadas serão aprofundadas pois consistem em uma etapa da pesquisa de Doutorado mencionada, o qual está em curso e as leituras da documentação produzida em campo estão sendo realizadas de forma constante, portanto, são análises parciais de uma pesquisa em andamento.

Ressaltamos a importância da Educação Infantil como a primeira etapa da Educação Básica Brasileira e, também, o primeiro contato com o conhecimento sistematizado e mediado. Neste sentido, é necessário estabelecer referênciais teórico-metodológicos com o foco nas habilidades do pensamento espacial, em oposição do espontaneísmo do conhecimento na infância.

O desenvolvimento do pensamento espacial a partir do universo infantil pode contribuir para a aprendizagem de princípios cartográficos, como os pontos de vista utilizados em uma representação gráfica. As 
atividades mobilizadoras dos pensamentos espaciais desempenham o papel fundamental para o desenvolvimento do pensamento geográfico, bem como da própria representação do espaço.

Partimos da relação integrada, pois entendemos a cartografia enquanto linguagem, que concretiza o pensamento espacial, imbuido de conhecimento geográfico, como localização, distância e conexão. É importante afirmar que compreendemos que a criança vive, experencia e apreende o espaço para depois, representá-la, o que envolve diversos processos cognitivos em relação aos conceitos de espaço e tempo. Portanto, o desenvolvimento da linguagem cartográfica se dá por meio de uma educação cartográfica e a representação é o resultado da relação intelectual com a realidade.

\section{Referências}

Arce, A. (2010). O referencial curricular nacional para a educação infantil (re) colocando o ensino como eixo norteador do trabalho pedagógico com crianças de 4 a 6 anos. En A. Arce e L. Martins (Ed.). Quem tem medo de ensinar na educação infantil?: em defesa do ato de ensinar (pp.14-36). Campinas: Alínea.

Carvalho, A. (2011). Uma metodologia de pesquisa para estudar os processos de ensino e aprendizagem em salas de aula. En F. Santos e I. Greca (Ed.) A pesquisa em ensino de ciências no Brasil e suas metodologias (pp. 13-47) Injuí.

Galian, C. (2012). O conhecimento de mundo na Educação Infantil como primeira aproximação do conhecimento científico. En M. Reis, M. Xavier e L. Santos. Crianças e Infâncias: educação, conhecimento, cultura e sociedade (pp. 19-32). São Paulo: Annablume.

Gersmehl, P. (2008). Teaching geography. New York: The Guilford Press.

Gersmehl, P. J. \& Gersmehl, C. A. (2007). Spatial Thinking by young children: neurologic evidence for early development and "educability". Journal of Geography, 5(106), 181-191.

Greig, P. (2004). A criança e seu desenho: o nascimento da arte e da escrita. Porto Alegre: Artmed.

Lastória, A.; Moraes, L.; y Fernandes, S. (2013). Diálogos sobre geografia escolar e linguagem cartográfica. En: A. Lastoria (Ed.) Diferentes Linguagens no contexto escolar: questões conceituais e apontamentos metodológicos (pp. 107-117). Florianópolis: Insular.

Lorenzato, S. (2006). Educação Infantil e Percepção Matemática. Campinas: Autores Associados.

Manning, M.; e Granströn, B. (2007). Debaixo da cama: uma viagem ao centro da Terra. São Paulo: Ática.

Vigotski, L. (1998). O desenvolvimento psicológico na infância. São Paulo: Martins Fontes.

Vigotski, L. (2009). A construção do pensamento e da linguagem. São Paulo: Martins Fontes. 